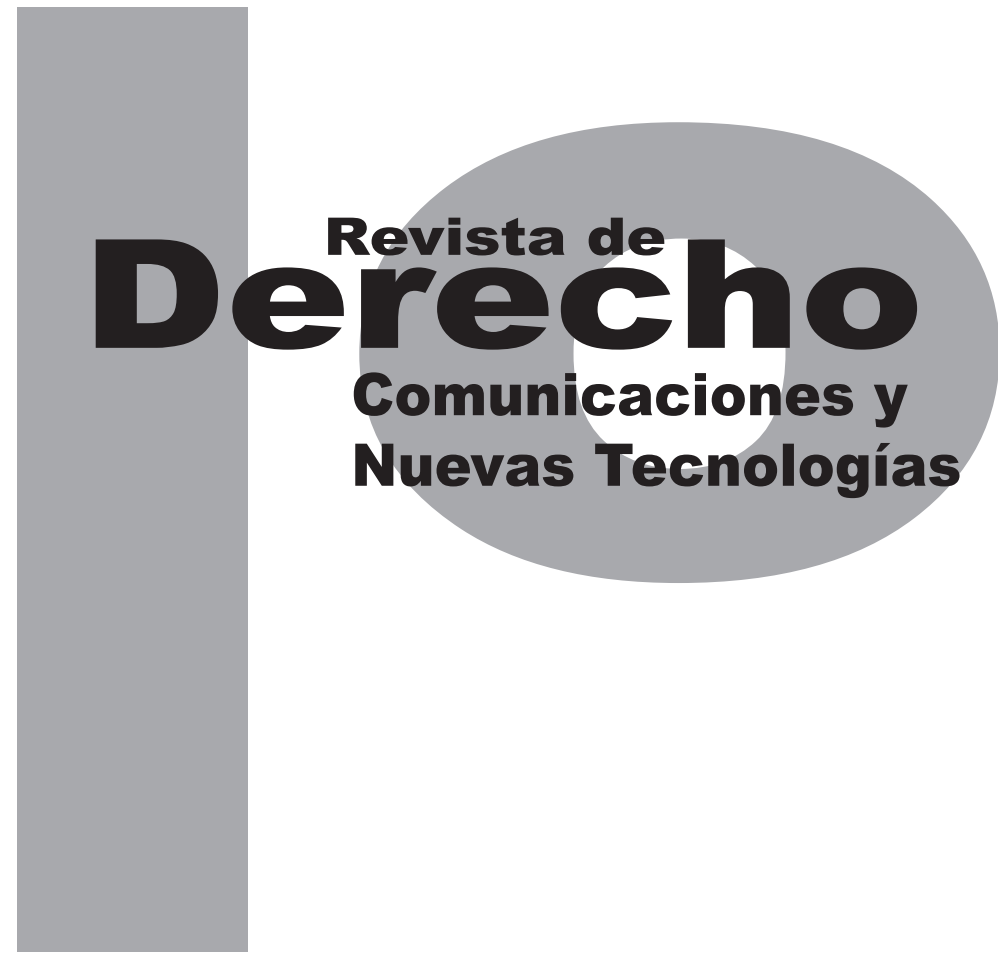

\title{
PROPIEDAD INTELECTUAL EN ACTIVIDADES DE TELEOBSERVACIÓN DE LA TIERRA DESDE EL ESPACIO DE LA COOPERACIÓN A LA PRIVATIZACIÓN
}

\author{
María Paula Macías díaz
}

Artículo de reflexión

DOI: http://dx.doi.org/10.15425/redecom.12.2014.14

\author{
Universidad de los Andes \\ Facultad de Derecho
}

Revista de Derecho, Comunicaciones y Nuevas Tecnologías

No.12, Julio - Diciembre de 2014. ISSN 1909-7786 


\section{Propiedad intelectual en actividades de teleobservación de la tierra desde el espacio. De la cooperación a la privatización}

\section{Resumen}

El fundamento del presente trabajo es analizar las diferentes posiciones doctrinales, a favor y en contra de la privatización de las actividades espaciales, para así poner de presente la inviabilidad de aplicar el régimen de propiedad intelectual en los datos derivados de la teleobservación de la Tierra desde el espacio, debido a que no está diseñado para regular la materia a razón del factor territorial que fundamenta el mencionado reglamento jurídico.

De igual forma, se planteará la necesidad de complementar la Resolución 41/65, sobre los Principios Relativos a la Teleobservación de la Tierra desde el Espacio, con disposiciones básicas de protección de derechos de propiedad intelectual que se fundamenten en el principio de cooperación internacional, para que así se pueda garantizar el acceso a los datos que se derivan de las actividades espaciales de teleobservación.

Palabras clave: teleobservación de la Tierra desde el espacio, principio de cooperación internacional, privatización, régimen de propiedad intelectual, datos primarios, datos elaborados, información analizada.

\section{Intellectual property in remote sensing activities of Earth from outer space. Cooperation to privatization}

\section{Abstract}

The purpose of this text is to analyze the different positions for and against the privatization of space activities in order to emphasize the failure of the application of intellectual property rules in the remote sensing data, all this, because that legal framework was not designed to regulate this kind of activity at the rate of the territorial factor.

On the other hand, the need to complement the Resolution 41/65 about the principles relating to remote sensing of the Earth from space will be explained with specific rules for the protection of intellectual property rights that are based on one of the three principles of Outer Space Law, the principle of international cooperation.

Keywords: remote sensing of the Earth from space, international cooperation, privatization, intellectual property regime, primary data, processed data, analysed information.

\section{Propriedade intelectual em atividades de tele observação da Terra desde o espaço. Da cooperação à privatização}

\section{Resumo}

O propósito do presente trabalho é analisar as diferentes posições doutrinais, a favor e contra, da privatização das atividades espaciais, para assim apresentar a inviabilidade de aplicar o regime de propriedade intelectual nos dados derivados da tele observação da terra desde o espaço, devido a que este regime não está desenhado para regular a matéria à razão do fator territorial.

De igual forma, será exposta a necessidade de complementar a Resolução 41/65 sobre os Princípios Relativos à Tele observação da Terra desde o Espaço, com disposições básicas de proteção de direitos de propriedade intelectual que se fundamentem no princípio de cooperação internacional, para que assim, se possa garantir o acesso aos dados que se derivam das atividades espaciais de tele observação.

Palavras-chave: tele observação da terra desde o espaço, princípio de cooperação internacional, privatização, regime de propriedade intelectual, dados primários, dados elaborados, informação analisada. 


\title{
Propiedad intelectual en actividades de teleobservación de la tierra desde el espacio* De la cooperación a la privatización
}

\author{
María Paula Macías Díaz ${ }^{* *}$
}

\section{SUMARIO}

Introducción - I. PLANTEAMIENTO GENERAL - A. Aproximación histórica y contextualización - B. Teleobservación y régjmen de propiedad - C. De los datos derivados de la teleobservación: datos primarios, datos elaborados e información analizada - II. REGULACIÓN JURÍDICA DE LA TELEOBSERVACIÓN DE LA TIERRA DESDE EL ESPACIO - A. Del consenso, la confianza y la cooperación internacional - B. Resolución 41/65 de la Asamblea General de las Naciones Unidas, de los Principios Relativos a la Teleobservación de la Tierra desde el Espacio - C. De la cooperación internacional - III. PRIVATIZACIÓN EN LAS ACTIVIDADES ESPACIALES - IV. RELACIÓN JURÍDICA DE LA PROPIEDAD INTELECTUAL EN ACTIVIDADES DE TELEOBSERVACIÓN - V. FUNDAMENTO Y PROPUESTA. DE LOS PRINCIPIOS RELATIVOS A LA REGULACIÓN DE PROPIEDAD INTELECTUAL DE DATOS DERIVADOS DE LA TELEOBSERVACIÓN DE LA TIERRA DESDE EL ESPACIO - VI. CONCLUSIONES - Bibliografía

Cómo citar este artículo: Macías, M. (Diciembre, 2014). Propiedad intelectual en actividades de teleobservación de la Tierra desde el espacio. Revista de Derecho, Comunicaciones y Nuevas Tecnologías, 12. Universidad de los Andes (Colombia).

** María Paula Macías Díaz, estudiante de derecho de la Universidad de los Andes en proceso de grado. Actualmente trabaja como abogada en la compañia Biomax S. A. Correo electrónico: mp.macias361@uniandes.edu.co. 
Introducción

El avance tecnológico y científico de las últimas décadas ha sido contemplado como un fenómeno característico del proceso de globalización. La actividad espacial de teleobservación de la Tierra ya no es considerada como una herramienta propia de las grandes potencias, sino como un instrumento asequible a todos los Estados -independientemente de su nivel de desarrollo-, el cual es usado para monitorear las condiciones ambientales, gestionar la eficiencia de los recursos e, igualmente, para predecir y prevenir desastres naturales previsibles e irresistibles (Kuriyama, 2010, p. 567). En términos generales, la función de estos satélites artificiales es observar el medio ambiente en sentido amplio, a saber, los recursos naturales renovables, la previsión del rendimiento de los cultivos, el petróleo y la exploración minera, entre otros (West, 1990, p. 405).

Por su parte, como bien se sabe, el principio fundamental del sector privado es el ánimo de lucro que, dentro del comercio de las actividades espaciales, está determinado por la inversión de agentes privados que en principio no están sujetos al derecho del espacio ultraterrestre (Diago, 2013, p. 34). Es por esta razón que se dificulta poder garantizar el principio de cooperación internacional dentro de las actividades de teleobservación de la Tierra desde el espacio debido a que, como sujetos privados, no buscan la finalidad de proveer un beneficio al interés común, pues por el contrario, su motivación es generar un bien económico particular.
Teniendo en cuenta lo anterior, el fundamento del presente trabajo es analizar las diferentes posiciones doctrinales, a favor y en contra de la privatización de las actividades espaciales, para así, poner de presente la inviabilidad de aplicar el régimen de propiedad intelectual existente en este tipo de actividades, debido a que no está diseñado para regular la materia a razón del factor territorial que fundamenta el mencionado reglamento jurídico.

De igual forma, se planteará la necesidad de complementar la Resolución 41/65, sobre los Principios Relativos a la Teleobservación de la Tierra desde el Espacio, con disposiciones básicas de protección de derechos de propiedad intelectual que se fundamenten en el principio de cooperación internacional, para que así se pueda garantizar el acceso a los datos que se derivan de las actividades espaciales de teleobservación.

\section{PLANTEAMIENTO GENERAL}

\section{A. Aproximación histórica y contextualización}

En la Resolución 41/65 de la Asamblea General de las Naciones Unidas (3 de diciembre de 1986), por medio de la cual se establecen los Principios Relativos a la Teleobservación de la Tierra desde el Espacio, se ha definido esta actividad como la "observación de la superficie terrestre desde el espacio, para fines de mejoramiento de la ordenación de los recursos naturales, de utilización de tierras y de protección del 
medio ambiente". Con fundamento en dichos principios, en el ámbito del derecho internacional, se considera que la finalidad de la teleobservación es que sea realizada en provecho e interés de todos los países, sea cual sea el grado de desarrollo económico, social, científico o tecnológico, y teniendo en cuenta las necesidades de cada uno de estos.

Los datos derivados de la actividad de teleobservación son clasificados según el grado de complejidad, elaboración e integración de la información obtenida, los cuales, a partir de los fines de la actividad misma, se deduce que están al alcance de todos los Estados miembros de las Naciones Unidas. Sin embargo, desde 1994 cuando Estados Unidos facultó a las compañías privadas para la construcción de satélites de uso comercial capaces de capturar imágenes de alta resolución, el factor de la privatización en las actividades espaciales empezó a modificar el panorama, pues trajo consigo la necesidad de aplicar por analogía las disposiciones jurídicas propias del régimen de propiedad intelectual, las cuales entraron a regular la protección de creaciones intelectuales producto del análisis y estudio de los datos provenientes de la información derivada de la teleobservación (Neagu, 2009, p. 53).

Dada la falta de regulación expresa de las actividades de la teleobservación - pues no hay un tratado específico que rija la materia-, la Resolución 41/65 es la única fuente que determina el desarrollo de la teleobservación con base en los principios consagrados en ella. Lo anterior, fundamenta el debate respecto a la categori- zación de los datos derivados de la teleobservación como información pública en virtud del principio de cooperación internacional, o como información privada debido al valor intelectual agregado que resulta de la interpretación y análisis de los datos obtenidos, y que la hace beneficiaria del régimen de propiedad intelectual.

Esta problemática se fundamenta en la relación entre 1) la limitada aplicación de disposiciones legales encaminadas a la protección de derechos de autor en los datos teleobservados y 2) las diferentes necesidades de los países en vía de desarrollo y aquellos desarrollados, pues esta interacción produce elementos de disuasión propios de abusos del régimen de propiedad intelectual en las actividades de teleobservación (West, p. 408).

Sin embargo, aunque a la luz del derecho internacional esta situación es contrarrestada directamente mediante la implementación de medidas tales como la constatación clara y expresa de los principios que rigen esta actividad y del Convenio de Berna para la Protección de las Obras Literarias y Artísticas, estas normas no son suficientes pues se deja el campo abierto a interpretaciones subjetivas tanto para los creadores intelectuales como para aquellos interesados en los datos teleobservados.

\section{B. Teleobservación y régimen de propiedad}

Partiendo de lo anterior, son evidentes las dificultades que representa para los países en vía de desarrollo el acceso a los datos derivados de 
la actividad espacial de la teleobservación de la Tierra desde el espacio, primero porque no tienen la capacidad económica para tener un satélite teleobservador propio, razón por la cual se ven en la necesidad de llegar a un tipo de acuerdo con otros países teleobservadores para así acceder a la información obtenida; y segundo, por los onerosos costos de los datos elaborados o la información analizada derivados de la teleobservación (Resolución 41/65, 1986, Principio I, Literales c) y d)).

Bajo este supuesto, pese a que en teoría ningún Estado debería comprar o vender la información derivada de las actividades de teleobservación en virtud del principio de cooperación internacional y de las demás motivaciones establecidas en la Resolución 41/65, en la práctica sucede lo contrario pues existe un mercado de datos que de por sí vulnera la escasa regulación legal sobre la materia y que además, transgrede dichas disposiciones por abusos de posición de dominio y la ejecución de prácticas monopólicas como consecuencia de la privatización, situación que hace aun más gravosa la problemática que se tiene como objeto de investigación.

El sector de la doctrina a favor de la privatización de los datos derivados de la teleobservación dispone como argumento principal que, debido a la finalidad esencial del régimen de propiedad intelectual de incentivar las creaciones intelectuales, y fomentar y proteger a quienes las desarrollan para así lograr el crecimiento social, cultural y económico de una sociedad, es necesaria la aplicación de esta disciplina del derecho para los denominados enhanced data por ser el resultado del análisis humano o electrónico de los raw data (West, p. 408, cursivas mías). Con respecto a lo anterior, esta corriente enfoca la problemática en determinar cuál es el régimen aplicable en relación con una legislación determinada, pues al no formar parte de ningún territorio estatal el espacio ultraterrestre, no queda clara cuál es la ley aplicable para dar protección efectiva a las creaciones intelectuales a razón de la inexistencia de disposiciones legales de propiedad en el derecho del espacio (Sterling, 2007, pp. 348-349). Sin embargo, considero que esta posición tiene un trasfondo meramente económico que busca dar un valor representativo y material a los datos elaborados e información analizada como productos novedosos dentro del sofisticado, oneroso y complejo mercado espacial, mas no representa un verdadero propósito de desarrollo, el cual supone la inclusión equitativa de la carga cultural, social y económica en una sola unidad.

Por su parte, el otro lado de la doctrina argumenta su posición en contra de la privatización de estos datos a favor de países en vía de desarrollo y de aquellos que no cuentan con un satélite propio, justificando que dicha limitación al acceso de información constituye una medida de exclusión, trato inequitativo y vulneración propia a la seguridad pública pues, debido a que los datos elaborados y analizados representan un beneficio propio para los países teleobservados, su política de distribución debería ser libre y de autónoma disposición en función del principio de cooperación internacional (Ling, 2010, pp. 442-443). 
En virtud de lo mencionado anteriormente, mi posición frente al problema trae como base fundamental uno de los umbrales rectores del derecho del espacio ultraterrestre, el principio de cooperación internacional. Para efectos de la investigación, esta disposición es entendida como la finalidad esencial de la actividad espacial de teleobservación, la cual debe ser realizada en provecho e interés de todos los países, sea cual sea el grado de desarrollo económico, social, científico o tecnológico. Pese a que en la práctica este principio es aislado pues representa un obstáculo para el crecimiento económico del mercado espacial, es necesaria una propuesta que garantice el acceso equitativo de todos los países a la información derivada de la teleobservación, a saber, datos primarios, elaborados e información analizada, por medio del cual se logre el equilibrio entre la propiedad intelectual y el derecho ultraterrestre.

Es así como el presente trabajo busca determinar, ¿en qué medida el régimen de propiedad intelectual de los datos elaborados e información analizada derivados de la actividad espacial de teleobservación, es contrario a los principios rectores del derecho del espacio ultraterrestre y a la Resolución 41/65? ¿En qué medida la privatización de la teleobservación vulnera los principios que rigen esta actividad espacial? ¿Cuáles son las alternativas que tienen los países en vía de desarrollo para poder acceder a la información recolectada por la teleobservación tomando como fundamento el principio de equidad y cooperación internacional?

\section{De los datos derivados de la teleobservación: datos primarios, datos elaborados e información analizada}

En este punto resulta oportuno establecer las diferentes etapas en la obtención de información mediante tecnologías satelitales de teleobservación (Williams, 2008, p. 25). El Principio I de la Resolución 41/65 establece que, para efectos de su contenido, se entiende por:

I. Datos primarios los "datos brutos recogidos mediante equipos de teleobservación transportados en un objeto espacial y que se transmiten o se hacen llegar al suelo desde el espacio por telemetría, en forma de señales electromagnéticas, mediante película fotográfica, cinta magnética, o por cualquier otro medio".

II. Datos elaborados los “productos resultantes de la elaboración de los datos primarios necesaria para hacer utilizables esos datos".

III. Información analizada aquella "información resultante de la interpretación de los datos elaborados, otros datos básicos e información procedente de otras fuentes", y;

\section{Actividades de teleobservación la "explota-} ción de sistemas espaciales de teleobservación, de estaciones de recepción y archivo de datos primarios y las actividades de elaboración, interpretación y difusión de datos elaborados".

En la etapa inicial, los satélites de teleobservación de la Tierra recogen los datos primarios que son enviados a las estaciones de la Tierra. Des- 
pués, se inicia la fase de preprocesamiento la cual consiste en rectificar distorsiones geométricas y radiométricas. Luego, se digitaliza la información de los datos primarios y a solicitud de los Estados teleobservados, se procesan las imágenes por medio de programas informáticos. Vale la pena aclarar que estos también cuentan con la posibilidad de solicitar a los países teleobservadores la clasificación de la información obtenida partiendo de las semejanzas y diferencias existentes entre los datos. Adicionalmente, es posible agregar información suplementaria que logre demostrar los resultados obtenidos de las imágenes satelitales (Williams, 2008, pp. 25-26).

Con el propósito de preservar el medio ambiente y de proteger a la humanidad, se entiende que la diferenciación entre los tipos de datos respecto a su grado de complejidad derivados de la teleobservación es de gran utilidad en el campo técnico y científico, sin embargo, bajo una interpretación positiva en el ámbito jurídico, sea cual sea la naturaleza de la información, esta debe ser asequible a todos los Estados que así la requieran en procura de la finalidad misma de cooperación internacional. Países como Brasil y China evidencian una correlativa respuesta a los lineamientos anteriormente planteados por medio de la implementación de políticas de distribución de esta información, pues justifican que no se puede limitar u obstaculizar la divulgación de los datos a favor de un Estado que lo necesita de forma inmediata por el hecho de ser un dato elaborado o analizado, ya que se estaría poniendo en riesgo su seguridad (Ling, 2010, p. 446).
Sin embargo, este ideal en la práctica no se perfecciona debido al mercado satelital que ha surgido con la privatización de las actividades espaciales, en particular, de la teleobservación de la Tierra desde el espacio. Se puede concluir entonces que, la aplicación del régimen de propiedad intelectual en los datos obtenidos representa una clara vulneración al principio de cooperación internacional por cuanto su comercialización se sobrepone a las disposiciones, motivaciones y finalidades del derecho del espacio ultraterrestre y, consecuentemente, a los principios relativos de la teleobservación.

Respecto a lo expuesto, hay que tener en cuenta que en ningún momento se está desconociendo el valor agregado que tienen los datos elaborados y la información analizada pues, indiscutiblemente, esta tiene que ser protegida por disposiciones legales pero no bajo las establecidas en el Convenio de Berna, lo cual nos lleva a pensar en la necesidad de establecer una serie de principios sobre propiedad intelectual para este tipo de actividades espaciales que vaya de la mano con la cooperación internacional.

\section{REGULACIÓN JURÍDICA DE LA TELEOBSERVACIÓN DE LA TIERRA DESDE EL ESPACIO}

\section{A. Del consenso, la confianza y la cooperación internacional}

En primer lugar, es necesario analizar la ley positiva del único texto que regula la materia, la Resolución 41/65 de los Principios Relativos 
a la Teleobservación de la Tierra desde el Espacio. Para esto, se debe iniciar con una breve descripción de las fuentes de obligaciones internacionales dentro del derecho del espacio ultraterrestre, a saber, tratados y resoluciones de derecho espacial, principios del derecho del espacio ultraterrestre y del derecho internacional y aquellos consagrados en la Carta de las Naciones Unidas.

Respecto a los tratados, estos deben ser ratificados por las partes del mismo para que pueda ser plenamente vinculante con fundamento en el principio de pacta sunt servanda y rebus sic stantibus, en síntesis, sobre la premisa "Ios pactos deben cumplirse, mientras las cosas sigan así". Sin embargo, es posible afirmar que aun así, si solo ha sido firmado mas no ratificado, los principios rectores del derecho del espacio ultraterrestre -1) uso pacífico, 2) no apropiación y 3) cooperación internacional, consagrados en el Tratado sobre los Principios que deben Regir las Actividades de los Estados en la Exploración y Utilización del Espacio Ultraterrestre de 1967le son aplicables y por tanto son de obligatorio cumplimiento con fundamento en el ius cogens ${ }^{1}$ y la costumbre internacional, ${ }^{2}$ conceptos seña-

1 Convención de Viena sobre el Derecho de Tratados. Artículo 53. Tratados que están en oposición con una norma imperativa de derecho internacional general ("jus cogens"). Es nulo todo tratado que, en el momento de su celebración, esté en oposición con una norma imperativa de derecho internacional general. Para los efectos de la presente convención, una norma imperativa de derecho internacional general es una norma aceptada y reconocida por la comunidad internacional de Estados en su conjunto como norma que no admite acuerdo en contrario y que solo puede ser modificada por una norma ulterior de derecho internacional general que tenga el mismo carácter.

2 Convención de Viena sobre el Derecho de Tratados. Artículo 38. Normas de un tratado que lleguen a ser obligatorias para terceros Estados en virtud de una costumbre internacional. Lo dispuesto en los artículos 34 a 37 no impedirá que una norma enunciada en un lados por la Convención de Viena sobre el Derecho de Tratados, el "tratado de tratados".

Los fundamentos del ius cogens y de la costumbre internacional son igualmente aplicables a las resoluciones. Estos tipos de fuentes forman parte del denominado soft law o "derecho blando", el cual ha sido definido por teóricos del derecho internacional como "el conjunto de reglas, disposiciones e instrumentos legales no vinculantes, que informan o interpretan la normativa jurídica vinculante o que representan promesas o expectativas acerca de conductas futuras" (Guzmán y Meyer, 2010, p. 174).

Las resoluciones son tomadas por consenso entre los Estados cuando hay acuerdo entre ellos sobre el contenido del texto, si bien jurídicamente no son vinculantes según el derecho internacional, el ser aprobadas por consenso supone que no hay oposición alguna en contra del cuerpo del documento, lo cual general confianza entre estos de que efectivamente sí se acogerá y se procurará el cumplimiento de lo acordado, reforzando así el principio de cooperación internacional.

Bajo este entendido, los principios del derecho espacial y del derecho internacional también son de obligatorio cumplimiento para todos los Estados. Respecto a los primeros, se puede afirmar que son motivados y fundamentados en el derecho internacional y en la Carta de las Naciones Unidas, partiendo de la necesidad de establecer lineamientos al servicio de la protec-

tratado llegue a ser obligatoria para un tercer Estado como norma consuetudinaria de derecho internacional reconocida como tal. 
ción al mundo y con el fin único de preservar el principio imperativo de la paz. Por tal razón, son de obligatorio cumplimiento para toda la comunidad internacional debido a que son considerados como una extensión que se ha desprendido de la matriz de los principios generales de la Carta, y esta, al haber sido signada por todos Ios Estados, se torna en sí misma imperativa y perentoria y transfiere su naturaleza a todas las fuentes derivadas de ella.

\section{B. Resolución 41/65 de la Asamblea General de las Naciones Unidas, de los Principios Relativos a la Teleobservación de la Tierra desde el Espacio}

Teniendo en cuenta lo anterior, se procederá a explicar la ley positiva de la Resolución 41/65 Ios Principios Relativos a la Teleobservación de la Tierra desde el Espacio. Para el teórico John Austin (2002), el derecho debe ser estudiado como lo que es mas no como debería ser (p. 30), es decir que para la interpretación del cuerpo normativo se debe ceñir estrictamente al significado positivo que en ella se consagra respecto a su motivación y finalidad de constituir un bien común para la sociedad.

EI Principio II de la resolución establece que:

Las actividades de teleobservación se realizarán en provecho e interés de todos los países, sea cual fuere su grado de desarrollo económico, social o científico y tecnológico y teniendo especialmente en cuenta las necesidades de los países en desarrollo.

Lo anterior indica de manera específica que el desarrollo de esta actividad va dirigida a pro- porcionar un provecho o beneficio a todos los países independientemente de su desarrollo con fundamento en el principio de cooperación internacional, el cual será explicado con mayor detenimiento más adelante. Bajo este entendido, cualquier disposición que sea contraria a representar un beneficio para los Estados, será declarada nula pues estos principios al ser justificados por el ius cogens, no admiten norma contraria a razón de su carácter perentorio. Por tanto, el uso de la teleobservación como herramienta para satisfacer un interés particular a favor de cualquier Estado, es totalmente contrario a las disposiciones que rigen esta actividad, representando así una vulneración a la normatividad espacial e internacional.

Por su parte, el Principio III de la resolución establece de manera específica que las disposiciones normativas del derecho internacional y del derecho del espacio ultraterrestre son consideradas como fuentes jurídicas aplicables al desarrollo de las actividades de teleobservación bajo los siguientes términos:

Las actividades de teleobservación se realizarán de conformidad con el derecho internacional, inclusive la Carta de las Naciones Unidas, el Tratado sobre los principios que deben regir las actividades de los Estados en la exploración y utilización del espacio ultraterrestre, incluso la Luna y otros cuerpos celestes, y los instrumentos pertinentes de la Unión Internacional de Telecomunicaciones.

Lo anterior refuerza la idea señalada en párrafos anteriores, en donde se estableció que las actividades espaciales, en concreto las de tele- 
observación de la Tierra desde el espacio, están sometidas a las disposiciones del derecho del espacio ultraterrestre y del derecho internacional -incluyendo la Carta de las Naciones- con fundamento en el ius cogens y en la finalidad de mantener y construir la paz.

El Principio IV dispone que:

Las actividades de teleobservación se realizarán de conformidad con los principios contenidos en el artículo I del Tratado sobre los principios que deben regir las actividades de los Estados en la exploración y utilización del espacio ultraterrestre, incluso la Luna y otros cuerpos celestes, en el cual se dispone en particular que la exploración y utilización del espacio ultraterrestre deberán hacerse en provecho y en interés de todos los países, sea cual fuere su grado de desarrollo económico y científico, y se establece el principio de que el espacio ultraterrestre estará abierto para su exploración y utilización en condiciones de igualdad. Estas actividades se realizarán sobre la base del respeto del principio de la soberanía plena y permanente de todos los Estados y pueblos sobre su propia riqueza y sus propios recursos naturales, teniendo debidamente en cuenta los derechos e intereses, conforme al derecho internacional, de otros Estados y entidades bajo la jurisdicción de estos. Tales actividades no deberán realizarse en forma perjudicial para los legítimos derechos e intereses del Estado observado.

La norma anterior constata nuevamente que la teleobservación de la Tierra desde el espacio debe realizarse en pro de todos los Estados sin importar su nivel de desarrollo, en virtud del principio de equidad y de la exploración y utiliza- ción del espacio ultraterrestre con fines pacíficos; e introduce el principio de soberanía plena de los Estados suponiendo que se deben proteger sus recursos y evitar cualquier amenaza contra los mismos que se puedan derivar de la práctica de esta actividad.

Así, el principio de soberanía también se ve inmerso en el Principio IX el cual señala que:

De conformidad con el artículo IV del Convenio sobre el registro de objetos lanzados al espacio ultraterrestre y con el artículo XI del Tratado sobre los principios que deben regir las actividades de los Estados en la exploración y utilización del espacio ultraterrestre, incluso la Luna y otros cuerpos celestes, el Estado que realice un programa de teleobservación informará de ello al Secretario General de las Naciones Unidas. Comunicará también, en la mayor medida posible dentro de lo viable y factible, toda la demás información pertinente a cualquier Estado, y especialmente a todo país en desarrollo afectado por ese programa, que lo solicite.

Sin embargo, este postulado también establece el deber de información de los países teleobservadores a los países teleobservados respecto de los datos derivados de dicha actividad espacial, y pone a disposición de los países en vía de desarrollo una protección especial aun más rigurosa con el fin último de garantizarle a los contrarios el acceso a la información.

Es así como se incorpora la obligación de los países teleobservadores de otorgar la información derivada de la actividad espacial a los Estados teleobservados bajo la finalidad de promover la cooperación internacional entre los mismos. Es 
preciso interpretar entonces que dentro de la puesta en acción de este principio se incluye la necesidad de que los países que realicen esta actividad, den a conocer información que sea útil para evitar fenómenos o desastres naturales que amenacen o perjudiquen a los Estados que están siendo teleobservados, como una medida de reciprocidad en concurrencia con el principio de cooperación.

Respecto a uno de los objetivos principales de la teleobservación, el Principio X de la Resolución 41/65, señala que esta actividad debe:

promover la protección del medio ambiente natural de la Tierra. Con tal fin, los Estados que participen en actividades de teleobservación y que tengan en su poder información que pueda prevenir fenómenos perjudiciales para el medio ambiente natural de la Tierra la darán a conocer a los Estados interesados.

Por su parte, el Principio XI establece que también debe:

promover la protección de la humanidad contra los desastres naturales. Con tal fin, los Estados que participen en actividades de teleobservación y que tengan en su poder datos elaborados e información analizada que puedan ser útiles a Estados que hayan sido afectados por desastres naturales o probablemente hayan de ser afectados por un desastre natural inminente, los transmitirán a los Estados interesados lo antes posible.

Es evidente que estas disposiciones buscan en términos generales el bien común para todos los Estados, sin embargo, su motivación va mu- cho más allá del simple interés conjunto pues en esencia, lo que busca es proteger a la humanidad. Esta protección se efectúa por medio de la difusión y promulgación de la información obtenida de la teleobservación para aquellos Estados que requieran de ella para salvaguardar la seguridad de la población y de los recursos naturales. Lo anterior supone una vez más el fundamento de cooperación internacional como herramienta necesaria para procurar el amparo y la defensa de todos los países, pero además, establece una doble protección a los Estados que no cuentan con satélites propios de teleobservación para que se haga efectivo su acceso a los datos derivados de dicha actividad.

El Principio XII señala un acceso justo y equitativo a la información derivada de la teleobservación, en especial respecto a los Estados que no cuentan con satélites propios que desarrollen esta actividad espacial, haciendo de los datos primarios y elaborados una fuente de inmediato acceso a favor del Estado teleobservado. Es posible afirmar que el costo de la información que plantea la norma, debe ser entendida como un valor "representativo" puesto que, en virtud de la finalidad misma de la teleobservación, la cual es fundada en el principio de cooperación internacional, ese costo no debe significar o representar un obstáculo para su acceso. Lo anterior, es justificado bajo los siguientes términos:

Tan pronto como sean producidos los datos primarios y los datos elaborados que correspondan al territorio bajo su jurisdicción, el Estado objeto de la teleobservación tendrá acceso a ellos sin discriminación y a un costo razonable. 
Tendrá acceso asimismo, sin discriminación y en idénticas condiciones, teniendo particularmente en cuenta las necesidades y los intereses de los países en desarrollo, a la información analizada disponible que corresponda al territorio bajo su jurisdicción y que posea cualquier Estado que participe en actividades de teleobservación.

De lo anterior se puede concluir que los datos derivados de la teleobservación son asequibles a todos los Estados que así los requieran, sin importar su nivel de desarrollo, pues la finalidad única de esta actividad espacial es representar un beneficio para toda la humanidad bajo una interpretación positiva de la norma. Por esta razón, el término "costo razonable" debe ser entendido como un factor inequívoco en pro del derecho a la accesibilidad de los datos derivados de la teleobservación, el cual debe ser libre, inmediato y equitativo con fundamento en el principio de cooperación internacional el cual será explicado en las siguientes líneas.

\section{De la cooperación internacional}

Vale la pena precisar que el principio de cooperación internacional en las actividades de teleobservación debe ser entendido a la luz del Artículo IX $\mathrm{X}^{3}$ del Tratado sobre los Principios que

3

Naciones Unidas. Asamblea General. Tratado sobre los principios que deben regir las actividades de los Estados en la exploración y utilización del espacio ultraterrestre, incluso la Luna y otros cuerpos celestes. Artículo IX. En la exploración y utilización del espacio ultraterrestre, incluso la Luna y otros cuerpos celestes, los Estados partes en el tratado deberán guiarse por el principio de la cooperación y la asistencia mutua, y en todas sus actividades en el espacio ultraterrestre, incluso en la Luna y otros cuerpos celestes, deberán tener debidamente en cuenta los intereses correspondientes de los demás Estados partes en el tratado. Los Estados partes en el tratado harán los estudios e investigaciones del espacio ultraterrestre, incluso deben Regir las Actividades Espaciales. Esta norma establece cuáles son los elementos que integran la cooperación internacional, a saber, 1) asistencia mutua; 2) no contaminación nociva o cambios desfavorables en el medio ambiente; y 3) la no intervención dañina por parte de un cualquier Estado. Ahora de manera específica, la concepción de cooperación internacional que trata el Principio V de la Resolución 41/65, establece que:

Los Estados que realicen actividades de teleobservación promoverán la cooperación internacional en esas actividades. Con tal fin, esos Estados darán a otros Estados oportunidades de participar en esas actividades. Esa participación se basará en cada caso en condiciones equitativas y mutuamente aceptables.

Bajo esta perspectiva, la interpretación positiva de esta disposición supone que, con el propósito de favorecer a todas las naciones y de garantizar un trato equitativo entre estas, los Estados que desarrollen actividades de teleobservación deben implementar medidas encaminadas a

la Luna y otros cuerpos celestes, y procederán a su exploración de tal forma que no se produzca una contaminación nociva ni cambios desfavorables en el medio ambiente de la Tierra como consecuencia de la introducción en él de materias extraterrestres, y cuando sea necesario adoptarán las medidas pertinentes a tal efecto. Si un Estado parte en el tratado tiene motivos para creer que una actividad o un experimento en el espacio ultraterrestre, incluso la Luna y otros cuerpos celestes, proyectado por él o por sus nacionales, crearía un obstáculo capaz de perjudicar las actividades de otros Estados partes en el tratado en la exploración y utilización del espacio ultraterrestre con fines pacíficos, incluso en la Luna y otros cuerpos celestes, deberá celebrar las consultas internacionales oportunas antes de iniciar esa actividad o ese experimento. Si un Estado parte en el tratado tiene motivos para creer que una actividad o un experimento en el espacio ultraterrestre, incluso la Luna y otros cuerpos celestes, proyectado por otro Estado parte en el tratado, crearía un obstáculo capaz de perjudicar las actividades de exploración y utilización del espacio ultraterrestre con fines pacíficos, incluso en la Luna y otros cuerpos celestes, podrá pedir que se celebren consultas sobre dicha actividad o experimento. 
asegurar el acceso para aquellos países que no cuentan con las herramientas para hacerlo.

Ahora bien, al unificar los elementos de la cooperación internacional consagrados en el Tratado del 67 y sus rasgos característicos definidos en el Principio IV, se puede afirmar que existen deberes y obligaciones en cabeza de los Estados que realizan este tipo de actividades espaciales para garantizar el acceso de otros países a la información derivada de la teleobservación, sin obstaculizar o hacer más gravoso el proceso para poder obtener dicha información.

Es pertinente aclarar que la carga de deberes y obligaciones en pro de la cooperación internacional no solo está en cabeza de los Estados que desarrollan actividades de teleobservación sino que también le son asignadas a las Naciones Unidas junto con sus organismos dependientes, tal y como consta en el Principio VIII, el cual establece que estos sujetos deben fomentar la cooperación de los Estados por medio de la asistencia técnica y de coordinación en la materia.

Todo lo anterior concurre en el análisis e interpretación del Principio XIII que reza lo siguiente:

Con el fin de promover e intensificar la cooperación internacional, especialmente en relación con las necesidades de los países en desarroIlo, el Estado que realice actividades de teleobservación de la Tierra desde el espacio ultraterrestre celebrará consultas con el Estado cuyo territorio esté observando, cuando este lo solicite, con miras a ofrecer oportunidades de participación y a aumentar los beneficios mutuos que produzcan estas actividades.
En esta norma se tiene en cuenta la diferencia entre los países que tienen elementos para desarrollar la teleobservación y los que no, y se les obliga a los primeros a consultar a petición de los Estados teleobservados para llegar a alternativas de participación en beneficio de los dos, preservando así el principio de cooperación internacional cuya finalidad es compartir la información derivada de la teleobservación.

Ahora, el Principio XIV, por medio del cual se establece que:

De conformidad con el artículo VI del Tratado sobre los principios que deben regir las actividades de los Estados en la exploración y utilización del espacio ultraterrestre, incluso la Luna y otros cuerpos celestes, los Estados que utilicen satélites de teleobservación serán responsables internacionalmente de sus actividades y deberán asegurar que ellas se efectúen de conformidad con los presentes principios y con las normas del derecho internacional, independientemente de que sean realizadas por organismos gubernamentales o entidades no gubernamentales o por conducto de organizaciones internacionales de las que formen parte esos Estados. El presente principio deberá entenderse sin perjuicio de la aplicabilidad de las normas del derecho internacional sobre la responsabilidad de los Estados en lo que respecta a las actividades de teleobservación.

Debe ser analizado minuciosamente pues es la primera referencia que supone la privatización de las actividades espaciales al señalar a las entidades no gubernamentales como sujetos que desarrollan actividades de teleobservación, tal y como se explicará en el siguiente capítulo. 


\section{PRIVATIZACIÓN DE LAS ACTIVIDADES ESPACIALES}

La privatización de las actividades espaciales surgió como respuesta estratégica para potencializar el mercado espacial y acelerar el crecimiento económico del comercio satelital de telecomunicaciones. Antes de este proceso, dichos servicios era proveídos por las organizaciones satelitales intergubernamentales e internacionales (ISO) tales como Intelsat, Inmarsat y Eutelsat; entidades que hoy en día son privadas y continúan siendo las mayores proveedoras de satélites de telecomunicaciones en el mundo (Ospina, 2005, p. 255).

Es importante destacar que tanto Intelsat como Inmarsat fueron privatizadas bajo términos y condiciones específicas dentro del Open Market Reorganization for the Betterment of International Telecommunications Act (ORBIT Act) en marzo de 2000, cuyo propósito era el de "promover completamente la competitividad del mercado global de los satélites de servicios de comunicación para el beneficio de sus consumidores [...] por medio de la privatización de organizaciones satelitales intergubernamentales" (ORBIT Act. Sección 2). Como consecuencia de este proceso, la Organización Internacional de Telecomunicaciones por Satélite (ITSO) ${ }^{4}$ y la Organización Internacional de Telecomunicaciones Móviles por Satélite (IMSO) -ambas de naturaleza inter-

4

En virtud del Artículo III del Acuerdo Relativo a la Organización Internacional de Telecomunicaciones por Satélite, se entiende que "el fin principal de ITSO es asegurar, mediante el Acuerdo de Servicios Públicos, que la sociedad suministre, sobre una base comercial, servicios internacionales públicos de telecomunicaciones, con el objeto de vigilar que se cumplan los principios fundamentales". gubernamental-, reemplazaron respectivamente a Intelsat e Inmarsat.

La privatización de Intelsat e Inmarsat incluyó como condición esencial en el Acuerdo de Servicios Públicos de ITSO, que las nuevas organizaciones (ITSO e IMSO) deben desempeñar el papel de supervisores para que así se pueda garantizar "el cumplimiento de las obligaciones de servicios públicos, realizadas por las empresas privadas". Sin embargo, analizando el panorama actual, es posible afirmar que la influencia de mencionados organismos intergubernamentales dentro del mercado satelital es muy baja debido a que está supeditada a los límites interpuestos por los sujetos privados como los bancos y las corporaciones financieras, quienes en últimas, son los propietarios y operadores de la mayoría de estos sistemas, dejando así un campo de acción e intervención muy reducido para las entidades estatales (Ospina, 2005, p. 256).

Los sujetos activos de este proceso de privatización de las actividades espaciales son, en primera instancia, los mismos Estados quienes, en pro del desarrollo nacional en el ámbito económico y social, han diseñado e impulsado la creación de sistemas satelitales tales como los de telecomunicaciones. Casos como el de México, Brasil, Argentina, España, Grecia, Turquía, India, Malasia, Tailandia, Corea, China, Egipto y los Emiratos Árabes, se han justificado en el discurso promocional del "avance tecnológico interno" para lanzar satélites cuya finalidad es mejorar las comunicaciones a nivel nacional o regional. Sin embargo, algunos de estos sistemas ya han sido adquiridos por sujetos privados 
motivados por intereses financieros, operacionales y en estrategias de mercado propias de la economía mundial.

Debido al desarrollo de nuevas tecnologías impulsadas por el proceso de privatización en las actividades espaciales, hoy en día no es posible concebir que el uso de la teleobservación de la Tierra desde el espacio es limitado a un campo de ordenación de recursos naturales, utilización de tierras y protección del medio ambiente, tal y como lo establece la Resolución 41/65 sobre los principios relativos a mencionada actividad.

Es cierto que la observación espacial es "el único medio para estudiar nuestro "sistema terrestre" de una manera rápida, global, sistemática y homogénea; [...] de estudiar los diferentes mecanismos que rigen el funcionamiento de los constituyentes de nuestro planeta, tan importantes como la atmósfera y los océanos, que determinan el clima, e incluso la corteza terrestre, cuyos movimientos son la causa de terremotos y erupciones volcánicas" (Centre National D'études Spatiales, 1996, p. 46); sin embargo, su aplicación y utilización sobrepasan los beneficios en cuanto al manejo de los recursos naturales para la agricultura, la prevención de desastres naturales y la meteorología.

El 21 de junio de 2006 Edward Morris, director de la Oficina de Comercialización Espacial, en conjunto con el National Oceanic and Atmospheric Administration and Information Service (NOAA) señalaron que las imágenes de la Tierra obtenidas por satélites de teleobservación representan múltiples beneficios para diferentes sectores de la economía global; para los gestores de planificación ciudadana, las compañías de seguros quienes utilizan las tomas para verificar daños, los medios de comunicación quienes añaden rutinariamente estas imágenes para ilustrar sus noticias y para tecnólogos dedicados al desarrollo de software en juegos y simuladores de vuelo entre otros (Craig, 2007, p. 552).

El sistema de posicionamiento global, más conocido como GPS (Global Positioning System), es una de las nuevas herramientas tecnológicas e innovadoras dentro del comercio internacional. Quizá el ejemplo más popular de este programa es la aplicación de Google Earth, disponible para dispositivos móviles, tabletas y computadores, que recientemente puso al alcance de cualquier persona las imágenes satelitales en Internet (Craig, 2007, p. 552). Para algunos, es posible afirmar que no existe ningún tipo de vulneración al acceso de los datos derivados de la teleobservación de la Tierra desde el espacio, pues tal y como sucede con este tipo de aplicaciones, las imágenes son asequibles gratuita y libremente a aquellos que navegan en la web.

Sin embargo, es aquí donde se debe analizar el factor de utilidad de los datos provenientes de satélites teleobservadores; si bien, la privatización de estos sistemas ha traído subvenciones particulares en ámbitos meramente privados, como fuente de información básica para uso educativo y de entretenimiento - lo cual va acorde al proceso de globalización que continúa regulando la gran mayoría de países-, para los sujetos de derecho espacial no representa una 
fuente de información suficiente en relación a las necesidades e intereses generales los mismos Estados.

Teniendo en cuenta lo anterior, es pertinente recordar que el fundamento esencial del sector privado es el ánimo de lucro determinado, en este caso, por la inversión de agentes externos no sujetos al derecho del espacio ultraterrestre (Diago, 2013, p. 34). Por esta razón consideramos que se haría un poco difícil garantizar el principio de cooperación internacional debido a que, como sujetos privados no buscan la finalidad de proveer un beneficio al interés común, pues al contrario, su motivación es generar un bien económico particular.

Sin embargo, las empresas privadas al estar vinculadas a un Estado, las obligaciones consagradas en la Resolución 41/65 hacen que de todas maneras estos organismos deban cumplir con las disposiciones previstas en el Principio XI -sobre la necesidad de promover la protección de la humanidad contra los desastres naturales por medio de la teleobservación-con lo cual la privatización se acomodaría a lo que en esencia ha querido proteger la norma de las Naciones Unidas.

\section{REGULACIÓN JURÍDICA DE LA PROPIEDAD INTELECTUAL EN ACTIVIDADES DE TELEOBSERVACIÓN}

Es pertinente iniciar este capítulo partiendo de la definición de propiedad intelectual. El convenio que establece la Organización Mundial de la
Propiedad Intelectual (OMPI) - Convention Establishing the World Intellectual Property Organization (WIPO)- del 4 de julio de 1967, en su Artículo II (VIII) ${ }^{5}$ dispone que este término hace referencia a los derechos de autor y de propiedad, la protección legal de estos y demás derechos relativos a la actividad intelectual (Kopal, 2008, p. 110), en síntesis, las creaciones de la mente, denominadas como invenciones, obras literarias y artísticas, símbolos, nombres e imágenes utilizadas en el comercio (Organización Mundial de la Propiedad Intelectual [OMPI] ¿Qué es la propiedad intelectual?).

Como se dijo anteriormente, el crecimiento acelerado del comercio espacial impulsado por la privatización ha demandado la necesidad de establecer normas que regulen la propiedad intelectual en este tipo de actividades, en específico sobre los datos elaborados e información analizada derivados de la teleobservación de la Tierra desde el espacio. La pregunta que se han

$5 \quad$ Artículo 2:

Definiciones:

A los efectos del presente Convenio se entenderá por:

«Propiedad intelectual», los derechos relativos:

- a las obras literarias, artísticas y científicas,

- a las interpretaciones de los artistas intérpretes y a las ejecuciones de los artistas ejecutantes, a los fonogramas y a las emisiones de radiodifusión

- a las invenciones en todos los campos de la actividad humana,

- a los descubrimientos científicos,

- a los dibujos y modelos industriales,

- a las marcas de fábrica, de comercio y de servicio, así como a los nombres y denominaciones comerciales,

- a la protección contra la competencia desleal, y todos los demás derechos relativos a la actividad intelectual en los terrenos industrial, científico, literario y artístico. 
hecho varios teóricos es si es válida, suficiente y eficiente la aplicación por analogía del régimen de propiedad intelectual, o si por el contrario, es necesaria la creación de un nuevo cuerpo normativo que regule la materia y se adhiera a las disposiciones legales del derecho internacional y del espacio ultraterrestre.

La primera posición, argumenta que la aplicación del régimen de propiedad intelectual existente es más que suficiente para regular otras áreas del derecho debido a su integridad y completitud como cuerpo normativo. Bajo este supuesto, se considera que la extensión de la Convención de Berna del 1886 por medio de la Revisión del Acta de Bruselas (1948) -en la cual se incorporaron provisiones específicas con la finalidad de garantizar los derechos exclusivos del autor para autorizar la radiodifusión de su trabajo o la reproducción del mismo por cualquier otro medio de difusión (Kopal, 2008, p. 110)-; y el Convenio de Bruselas sobre la Distribución de Señales Portadoras de Programas Transmitidas por Satélite del 21 de mayo de 1974 , son muestras de la amplitud y el bagaje del compendio legal, el cual, para este sector de la doctrina, se adecua perfectamente a las especificaciones técnicas y jurídicas que demanda la regulación de la propiedad intelectual en actividades espaciales.

Sin embargo, es factible suponer que aunque dicha normatividad tiene consideraciones que pueden ser utilizadas en el derecho del espacio, no son suficientes para satisfacer a cabalidad la regulación de especificidades propias de actividades espaciales como lo es la teleobserva- ción de la Tierra desde el espacio, en donde los datos que se derivan de su desarrollo ponen de presente la disyuntiva entre el principio de cooperación y el valor económico de estos.

Por su parte, respecto a la posición a favor de la creación de un cuerpo normativo que regule la propiedad intelectual en actividades de teleobservación, teóricos como Vladimir Kopal (2008) han señalado que a pesar de ser necesaria su estructuración, no es indispensable crear un nuevo sistema jurídico enfocado única y exclusivamente en la materia; para ellos, es más que suficiente la instauración de una apéndice especial adherida a la Convención de Berna que trate la propiedad intelectual en conexidad a las actividades espaciales (p. 110).

Mi posición frente al tema, contempla la absoluta necesidad de estructurar una serie de principios relativos a la regulación de propiedad intelectual en las actividades espaciales de teleobservación de la Tierra, que se adhieran a la Resolución 41/65, es decir, que sean independientes y autónomos a cualquier convenio, acuerdo o tratado internacional que trate sobre el régimen de creaciones intelectuales - con fundamento en el principio de especialidad normativa, en donde la regulación más específica tiene prioridad sobre las demás- pues en este caso, dichas disposiciones normativas deben tener sustento bajo el amparo del derecho espacial.

Así las cosas, estas directrices básicas sobre propiedad intelectual deben fundamentarse en los principios relativos de la teleobservación consagrados en la Resolución 41/65, en los 
principios rectores del derecho espacial, a saber, 1) uso pacífico, 2) no apropiación y 3) cooperación internacional para que se logre llegar a la finalidad de preservar la seguridad de la humanidad y resguardar los recursos naturales.

\section{FUNDAMENTO Y PROPUESTA. DE LOS PRINCIPIOS RELATIVOS A LA REGULACIÓN DE PROPIEDAD INTELECTUAL DE DATOS DERIVADOS DE LA TELEOBSERVACIÓN DE LA TIERRA DESDE EL ESPACIO}

El profesor Kopal (2008) identifica dos problemas principales derivados de la utilización de los datos obtenidos por actividades de teleobservación, el primero es la fiabilidad e independencia de la información y el segundo, la accesibilidad a esta (p. 71). Considera que la solución a esta problemática radica en la necesidad de buscar un balance entre intereses privados y públicos (p. 71), y entre el interés global y nacional (Onoda, 2005, pp. 10-19) para así poder lograr una efectiva utilización de los recursos naturales de la Tierra.

Partiendo de la definición de teleobservación consagrada en la Resolución 41/65, es posible identificar la distinción ente el segmento del espacio y su opuesto y complementario, el segmento terrestre de las operaciones de los satélites teleobservadores. Se entiende que en las funciones propias de la operación espacial concurre la recolección, grabación y transmisión de los datos obtenidos de la superficie terrestre a la Tierra, mientras que los otros, tienen la fun- ción de recibir, convertir e interpretar los datos que son enviados por el segmento del espacio (Kopal, 2008, p. 71). Para muchos teóricos del derecho espacial, este proceso no representa ningún problema respecto al régimen de propiedad intelectual en las actividades de teleobservación, pues consideran que la discusión se fundamenta en la distribución de estos datos.

Sin embargo, mi posición frente al tema toma distancia de este planteamiento -el contemplar la disyuntiva únicamente en la fase de distribución-, pues es en el proceso operacional espacial y terrestre donde se presenta la raíz de la discusión sobre la propiedad intelectual en los datos derivados de la teleobservación. Si bien es cierto, la "creación intelectual" es realizada por especialistas en la Tierra, los elementos constitutivos de la información analizada son obtenidos por el seguimiento, manejo y tratamiento de la recolección de datos espaciales, en donde es más que evidente la intervención de actividades propias del derecho del espacio ultraterrestre.

Lo anterior se justifica sobre dos disposiciones; la primera es que el simple hecho de que sea posible tener acceso a la observación total del globo terráqueo para obtener el conocimiento de esta información desde una plataforma espacial -a saber, desde los satélites artificiales de teleobservación-, pone en evidencia que esta actividad es propia del derecho del espacio ultraterrestre y que, por ende, debe regirse por las disposiciones normativas sobre la materia. La segunda, que los datos derivados de dicha actividad son espaciales y, por tanto, deben es- 
tar bajo una normativa especial diferente al régimen "terrestre" de propiedad intelectual.

Así las cosas, el tema de la distribución de los datos se deriva como consecuencia directa del proceso de operaciones espaciales y terrestres, y es en esta etapa donde se evalúa el factor territorial del régimen de propiedad intelectual. Bajo el análisis del elemento de territorialidad, se pretende determinar la jurisdicción aplicable en relación al lugar al que pertenecen las creaciones intelectuales; sin embargo, dentro del ámbito espacial, los operadores privados propietarios de satélites de teleobservación dan solución a esta cuestión estableciendo que el cuerpo normativo aplicable es el de el Estado de registro que lanzó el objeto espacial propiedad del sujeto privado. ${ }^{6}$

No obstante, debido a que 1) el espacio ultraterrestre no forma parte integral de la soberanía de ningún Estado tal y como lo establece la Constitución Espacial -Tratado de 1967-7, y 2)

6 El Artículo I del Convenio sobre el registro de objetos lanzados al espacio ultraterrestre, aprobado por la Asamblea General en su resolución 3235 (XXIX) del 12 de noviembre de 1974 establece que, para efectos del tratado:

“a) Se entenderá por "Estado de lanzamiento":

i) Un Estado que lance o promueva el lanzamiento de un objeto espacial;

ii) Un Estado desde cuyo territorio o desde cuyas instalaciones se lance un objeto espacial;

b) El término "objeto espacial" denotará las partes componentes de un objeto espacial, así como el vehículo propulsor y sus partes;

c) Se entenderá por "Estado de registro" un Estado de lanzamiento en cuyo registro se inscriba un objeto espacial de conformidad con el artículo II."

7 El Artículo II del Tratado sobre los principios que deben regir las actividades de los Estados en la exploración y utilización del espacio ultraterrestre, incluso la Luna y otros cuerpos celestes, aprobado por que las actividades de teleobservación de la Tierra desde el espacio son desarrolladas en esta área extraterritorial, no le es oponible la jurisdicción de ningún Estado diferente a la normatividad comprendida en el derecho espacial. Este es el argumento sustancial que justifica la imposibilidad de aplicar por analogía el régimen de propiedad intelectual para los datos derivados de la teleobservación y, que a su vez, fundamenta la necesidad de crear disposiciones jurídicas que constituyan unos principios especializados que regulen los aspectos legales de los datos obtenidos por el desarrollo de actividades espaciales teleobservadoras.

No es posible negar la estimulación y el impulso que ha generado el desarrollo progresivo de las actividades espaciales dentro del la economía mundial. Es preciso saber que la privatización de organismos internacionales, como SPOT y Landsat, ha ido de la mano con la evolución y modificación de leyes y reglamentos de orden nacional e internacional, para garantizar un "juego" transparente entre el derecho espacial y las empresas privadas (OECD, 2011, p. 33).

Es precisamente esta relación y dependencia entre el adelanto de nuevas tecnologías espaciales y la necesidad de ampliar el derecho lo que justifica que, para nuestro caso, las disposiciones relativas a la propiedad intelectual sean estructuradas bajo principios complementarios a la Resolución 41/65.

\footnotetext{
la Asamblea General en su resolución 2222 (XXI) del 19 de diciembre de 1966, establece que "El espacio ultraterrestre, incluso la Luna y otros cuerpos celestes, no podrá ser objeto de apropiación nacional por reivindicación de la soberanía, uso u ocupación, ni de ninguna otra manera.".
} 
En términos generales, el derecho es progresivo y cambiante, y se debe ir adecuando a nuevas situaciones o requerimientos que demandan una regulación legal; no es posible que la realidad se ajuste a las disposiciones normativas, al contrario, es el derecho el que debe adaptarse a los cambios. En la rama del derecho ultraterrestre, esta observancia cobra aún más fuerza a razón del acelerado desarrollo tecnológico y científico, y de los avances en el ámbito espacial que determinan y demandan paso a paso la amplitud de disposiciones jurídicas.

Es por esta razón que se justifica la necesidad de un derecho flexible que en un futuro permita su modificación para adecuarse a nuevas realidades tecnológicas. En mi concepto, la mejor forma de permitir dicha amplitud normativa es por medio de las resoluciones, que tal y como fue explicado en capítulos anteriores, hacen parte del soft law.

En virtud de lo expuesto, la propuesta del presente trabajo fundamenta la necesidad de complementar - por medio de una nueva resolución- las normas del Anexo 41/65 con la formulación de principios relativos a la regulación de propiedad intelectual de datos derivados de la teleobservación de la Tierra desde el espacio, como directrices básicas y esenciales que rijan la materia, basándose en el principio de cooperación internacional y en la finalidad propia de la protección de creaciones intelectuales, con el propósito de garantizar el acceso a dicha información en provecho e interés de todos los países, sea cual sea su grado de desarrollo; para que a su vez, sea factible la modificación de ta- les disposiciones teniendo en cuenta las futuras demandas de regulaciones jurídicas que van de la mano con el desarrollo de nuevas tecnologías espaciales.

\section{CONCLUSIONES}

Con base en el análisis expuesto a lo largo del texto, es necesaria la conformación de principios que contengan disposiciones básicas encaminadas a proteger derechos de propiedad intelectual de los datos provenientes de actividades de teleobservación satelital, con el fin de garantizar la protección de derechos legítimos sin que por esto se obstaculice o interrumpa el acceso a los datos por parte de países teleobservados que requieren dicha información con fundamento en el principio de cooperación internacional (Asamblea General de las Naciones Unidas, 2003).

Su justificación toma cimientos bajo la imposibilidad de aplicar por analogía el régimen de propiedad intelectual en razón del factor de territorialidad -el cual es entendido como elemento sustancial que fundamenta el mencionado reglamento jurídico-, debido a que el espacio ultraterrestre no forma parte integral de la soberanía de ningún Estado, tal y como lo establece el Tratado de 1967, y que las actividades de teleobservación de la Tierra desde el espacio son desarrolladas en esta área extraterritorial. Por ende, no le es oponible ninguna jurisdicción diferente a la normatividad comprendida en el derecho espacial y, a falta de esta, se hace necesaria la estructuración de principios que regulen la materia. 
Es así como la privatización de actividades espaciales va de la mano con la evolución y modificación normativa, bien sea a nivel nacional o internacional, en pro de garantizar una interacción transparente entre el derecho espacial y las empresas privadas, en donde la ecuación lógica es que el derecho se debe acoplar a la realidad tecnológica y científica para regular nuevas áreas que demandan disposiciones jurídicas.

Bajo el soft law, es posible otorgarle flexibilidad al derecho para que en un futuro se puedan ajustar nuevas reglas o instrumentos legales a los avances y desarrollos del comercio espacial, razón por la cual es pertinente que los principios relativos a la regulación de propiedad intelectual de datos derivados de la teleobservación de la Tierra desde el espacio se adhieran a la Resolución 41/65 del 3 de diciembre de 1986.

De igual forma como supuesto provisional, se podría plantear una nueva alternativa en donde los países teleobservadores, bajo el principio de colaboración, hagan alianzas estratégicas que garanticen la participación de los países teleobservados en el desarrollo de esta actividad para que así haya aporte intelectual por parte de estos sujetos y no sea plausible la compra y venta de esta información, con el fin de que sea viable esta disyuntiva de acuerdo con el principio de cooperación internacional.

En virtud de los argumentos expuestos, este trabajo nos Ileva a concluir que;

1. La problemática de la propiedad intelectual de los datos derivados de las actividades de te- leobservación de la Tierra desde el espacio -en específico los datos elaborados e información analizada- radica en la aplicación por analogía del régimen de propiedad intelectual consagrado en la Convención de Berna.

2. Debido a que el espacio ultraterrestre no forma parte integral de la soberanía de ningún Estado, y que las actividades de teleobservación de la Tierra desde el espacio son desarrolladas en esta área extraterritorial, no le es oponible dicho régimen.

3. Por lo anterior, es necesaria la complementación de la Resolución 41/65 con principios relativos a la regulación de propiedad intelectual de datos derivados de la teleobservación de la Tierra desde el espacio.

\section{Bibliografía}

Acta de Bruselas. (1948). Convención de Berna para la Protección de las Obras Literarias y Artísticas, firmada el 9 de septiembre de 1886, completada en París el 4 de mayo de 1896, revisada en Berlín el 13 de noviembre de 1908, completada en Berna el 20 de marzo de 1914, revisada en Roma el 2 de junio de 1928 y revisada en Bruselas el 26 de junio de 1948. Recuperado de

http://www.wipo.int/wipolex/es/wipo_treaties/ text.jsp?file_id=278723

Centre National D'études Spatiales (1996). Spciété Européenne de propulsion, Palais de la Découverte. L`Espace, comment ça marche? 
À quio ça sert?. Versión Española preparada por Jesús Sánchez y José María Sarasola. El espacio, ¿Cómo funciona? ¿Para qué sirve? Madrid.

Craig, B. (2007). Online Satellite and Aerial Images: Issues and Analysis. North Dakota Law Review, 83 (2), 547-578.

Cromer, J. (2006). How on Earth Terrestrial Laws Can Protect Geospatial Data. Journal of Space Law, 32 (2), 253-292.

DeSaussure, H. (1989). Remote Sensing SateIlite Regulation by National and International Law. Rutgers Computer \& Technology Law Journal (15), 351-376.Diago, P. (2013). Satélites de teleobservación de la Tierra: Aspectos técnicos y jurídicos (tesis de pregrado). Universidad de los Andes. Facultad de Derecho, Bogotá, Colombia.

Endsley, M. (1987). Remote Sensing for Public Safety. Santa Clara Computer \& High Technology Law Journal, 3 (1), 191-211.

Gillon, T. (2008) Regulating Remote Sensing Space Systems in Canada- New Legislation for a New Era. Journal of Space Law, 34 (1), 19-32.

Guzmán, A. y Meyer, T. (2010). International Soft Law. Journal of Legal Analysis, 2 (1), 171-225.

Kopal, V. (2008). An Introduction to Space Law. Kluwer Law International. Third Revised Edition. Wolters Kluwer, Law \& Business.
Krafft, S. (1981). In Search of a Legal Framework for the Remote Sensing of the Earth from Outer Space. Boston College International and Comparative Law Review , 4 (2), 453-476.

Kuriyama, I. (2010). Environmental Monitoring Cooperation Paves the Way for Common Rules on Remote Sensing Activities Among the Pacific Rim. Journal of Space Law, 36 (2).

Ling, Y. (2010). Remote Sensing Data Distribution and Application in the Environmental Protection, Disaster Prevention, and Urban Planning in China. Journal of Space Law, 36 (2), 435-457.

Naciones Unidas. Asamblea General. (1986). Resolución 41/65 del 3 de diciembre de 1986.

Naciones Unidas. (1994). Estudio sobre la aplicación de medidas de fomento de la confianza en el espacio ultraterrestre. Centro de Asuntos de Desarme. Informe del Secretario general. Nueva York, Estados Unidos.

Naciones Unidas. Asamblea General. Comisión sobre la Utilización del Espacio Ultraterrestre con Fines Pacíficos. Subcomisión de Asuntos Jurídicos. (2003). ¿Por qué es necesaria una convención internacional relativa a la teleobservación de la Tierra desde el espacio ultraterrestre? Documento de trabajo presentado por el Brasil.

Neagu, C. (2009). Political and legal issues on Satellite Remote Sensing. Use of Artificial Sa- 
tellites in Remote Sensing. Lex et Scientia International Journal, XVI (2). 50-69.

OMPI (Organización Mundial de la Pr opiedad Intelectual). (1967). Convenio que establece la Organización Mundial de la Propiedad Industrial. Firmado en Estocolmo el 14 de julio de 1967 y enmendado el 28 de septiembre de 1979.

OMPI (Organización Mundial de la Propiedad Intelectual). ¿Qué es la propiedad intelectual? Recuperado de http://www.wipo.int/export/ sites/www/freepublications/es/intproperty/450/wipo_pub_450.pdf

OMPI (Organización Mundial de la Propiedad Intelectual). (21 de mayo de 1974). Convenio sobre la distribución de señales portadoras de programas transmitidas por satélite. Bruselas.

Onoda, M. (2005). Global Earth Observation for Compliance of International Environmental
Agreements. Proceedings 48th Colloquium. Fukuoka.

Steele, L. J. (1991). View from on High: Satellite Remote Sensing Technology and the Fourth Amendment. High Technology Law Journal, 6 (2), 317-334.

Stering, J. A. L. (2007). Space Copyright Law: The New Dimension: A Preliminary Survey and Proposals. Journal of the Copyright Society of the USA, 54 (2-3), 1-66.

West, R. (1990). Copyright Protection for Data Obtained by Remote Sensing: How the Data Enhancement Industry Will Ensure Access for Developing Countries. Northwestern Journal of International Law \& Business, 11 (2), 403.

Williams, S. (2008). La información obtenida por tecnologías espaciales ante el derecho internacional. Enlace V.5 N.2. Maracaibo, Venezuela. 